\title{
Genetic diversity and population differentiation of small giant clam Tridacna maxima in Comoros islands assessed by microsatellite markers
}

Nadjim Ahmed Mohamed ${ }^{1}$, Qian Yu ${ }^{1}$, Mohamed Ibrahim Chanfi ${ }^{2}$ Yangping Li', Shi Wang ${ }^{1}$, Xiaoting Huang ${ }^{1 *}$ and Zhenmin Bao ${ }^{1 *}$

\begin{abstract}
Small giant clam, Tridacna maxima, widely distributed from French Polynesia to East Africa, has faced population declines due to over-exploitation. Comoros islands are an important biogeographic region due to potential richness of marine species, but no relevant information is available. In order to facilitate devising effective conservation management plan for T. maxima, nine microsatellite markers were used to survey genetic diversity and population differentiation of 72 specimens collected from three Comoros islands, Grande Comore, Moheli and Anjouan. A total of 51 alleles were detected ranged from 2 to 8 per locus. Observed and expected heterozygosity varied from 0.260 to 0.790 and from 0.542 to 0.830 , respectively. All populations have high genetic diversity, especially the population in Moheli, a protected area, has higher genetic diversity than the others. Significant heterozygote deficiencies were recorded, and null alleles were probably the main factor leading to these deficits. $F_{S T}$ value indicated medium genetic differentiation among the populations. Although significant, AMOVA revealed $48.9 \%$ of genetic variation within individuals and only a small variation of $8.9 \%$ was found between populations. Gene flow was high $(N m=12.40)$ between Grande Comore and Moheli, while lower $(\mathrm{Nm}=1.80)$ between Grande Comore and Anjouan, explaining geographic barriers to genetic exchanges might exist in these two islands. Global gene flow analysis $(\mathrm{Nm}=5.50)$ showed that larval dispersal is enough to move between the islands. The high genetic diversity and medium population differentiation revealed in the present study offer useful information on genetic conservation of small giant clams.
\end{abstract}

Keywords: Tridacna maxima, Comoros islands, Genetic diversity, Population differentiation, Gene flow, Marine protected areas

\section{Background}

The giant clam subfamily Tridacninae (Schneider and Foighil 1999) is the most widespread of the bivalves and is distributed throughout the Red sea and Indo-Pacific Ocean, from French Polynesia to East Africa (bin Othman et al. 2010). There are currently eight species from the genus Tridacna in the world: Tridacna. gigas (Linnaeus, 1758), T. maxima (Röding, 1798), T. crocea

\footnotetext{
*Correspondence: xthuang@ouc.edu.cn; zmbao@ouc.edu.cn 1 Key Laboratory of Marine Genetics and Breeding, College of Marine Life Sciences, Ocean University of China, Qingdao 266003, China

Full list of author information is available at the end of the article
}

(Lamarck, 1819), T. squamosa (Lamarck, 1819), T. derasa (Röding, 1798), T. tevoroa (Lucas, Ledua and Braley, 1991), T. rosewateri (Sirenko and Scarlato, 1991), T. costata (Roa-Quiaoit, Kochzius, Jantzen, Zibdah and Richter, 2008) (bin Othman et al. 2010). Recently, T. noae was separated from T. maxima by their genetic and morphological description (Su et al. 2014). Among these bivalves, T. maxima has commonly the largest distribution range (Lucas 1988). All those giant clams are settled on the coral reef in shallow water and live in symbiotic photosynthetic with xanthophyllae algae (genus 
Symbiodinium) that grow in the mantle tissues (Soo and Todd 2014).

Like other marine bivalves, small giant clam species ( $T$. maxima) are sedentary as adults, reproduce by broadcast spawning with high fecundity ( $>10^{6}$ eggs per female), and have pelagic larval dispersal about 9 days (Lucas 1988). Based on these aspects, population genetics studies can provide more information about the ecological interactions, larval dispersal, distribution patterns, as well as evolution of the species. To date, most of studies have been conducted on T. maxima about spawning (Lucas 1994; Soo and Todd 2014), larval and post-larval development (Jameson 1976), and growth (Hart et al. 1998; Smith 2011; Toonen et al. 2011). Whereas only a few studies have been done on genetic diversity and genetic structure of T. maxima. Indeed, genetic variations studies using allozyme analysis (Campbell et al. 1975; Laurent et al. 2002) and, recently, mitochondrial markers (Nuryanto and Kochzius 2009), have provided information on highly genetic variability, larval dispersal and also the connectivity of different sites of Indo-Pacific Ocean that can be explained by marine currents or geographic isolation (Benzie and Williams 1992a, b).

Small giant clam is listed in Appendix II of CITES (United Nations Convention on International Trade in Endangered Species of Wild Fauna and Flora) and classified as lower risk conservation dependent on the IUCN (International Union for Conservation of Nature) Red List of Threatened Species. This status indicates that the population densities have declined in a large geographical region by their overexploitation and the degradation of their natural habitat (Lucas 1994; bin Othman et al. 2010; Hui et al. 2011). It seems to be still abundant according to the population densities data in some part of countries (Australia, up to $3.83 \times 10^{1}$ individuals per $\mathrm{m}^{2}$ and French Polynesia, 5.84 per $\mathrm{m}^{2}$, for instance, see bin Othman et al. 2010). Therefore, it is crucial to intensify the conservation efforts of marine biodiversity as well as to preserve the natural marine species for sustainable development.

Comoros islands are separated from each other by a small distance, which indicate that the area is relatively narrow geographically (Fig. 1). Despite that, the area benefit a considerable interest in conservation due to the presence of abundant marine species, such as T. maxima but no relevant information is available to now. Recently, a research was conducted to identify and determine the marine mollusks species in Comoros islands using the photo-identification method and documentation of previous studies (Ramadhoini and Nirina, unpublished). Likewise an ecologic description have been studied on Tridacnidea family from Mayotte island (Deuss et al.
2013). Some microsatellite primers were developed from T. maxima by Grulois et al. (2014) and showed very high genetic diversity. In this study, we selected nine microsatellite markers (Grulois et al. 2014) to estimate the level of genetic diversity of $T$. maxima distributed in three islands of Comoros including Grande-Comore (Gc population), Anjouan (An population) and Moheli (Mo population). At the same time, we investigated the population differentiation in order to implement the conservation strategies of the T. maxima.

\section{Methods}

\section{Sample collection and DNA extraction}

Small giant clams $(n=72)$ were collected randomly between intertidal and subtidal zones at depth range of $0-20 \mathrm{~m}$ either by snorkeling or hand picking in three different localitions through the coral reefs of GrandeComore (Gc), Anjouan (An) and Moheli (Mo) in June 2015 (Fig. 1; Table 1). The geographic distance between the study areas is approximatively 100, 140 and $70 \mathrm{~km}$, between Gc-Mo, Gc-An, and Mo-An, respectively. For all specimens found, GPS positions were recorded and shells were measured (maximum length) using Vernier calipers.

Adductor muscles were taken, rinsed and preserved in $95 \%$ ethanol until DNA preparation. Genomic DNA was extracted following the protocol described by Zhan et al. (2009). The DNA was checked on $1 \%$ agarose gel and the concentration was determined for each sample using NanoView spectrophotometer, afterwards stored at $-20{ }^{\circ} \mathrm{C}$ prior to genetic analysis performed.

\section{SSR amplification and genotyping}

Individual genotypes were assessed using nine microsatellite markers (Grulois et al. 2014) (Table 2). PCR amplifications were performed in a final volume of $10 \mu \mathrm{l}$ containing 20-50 ng of genomic DNA, $10 \mu \mathrm{M}$ of each primer, $0.2 \mathrm{mM}$ dNTPs (Takara Bio Inc.), $10 \times$ PCR buffer (Takara Bio Inc.), and $0.5 \mathrm{U}$ Taq DNA polymerase (Takara Bio Inc.). Reactions were carried out on a thermal cycler (Bio-Rad Laboratories, Inc.) using the following steps: an initial denaturing step at $95{ }^{\circ} \mathrm{C}$ for $5 \mathrm{~min}$, followed by 35 cycles of $95^{\circ} \mathrm{C}$ for $30 \mathrm{~s}, 54^{\circ} \mathrm{C}$ for $45 \mathrm{~s}$ and $72{ }^{\circ} \mathrm{C}$ for $45 \mathrm{~s}$ with a final extension at $72{ }^{\circ} \mathrm{C}$ for $5 \mathrm{~min}$. PCR products were electrophoresed on $10 \%$ polyacrylamide gel using $1 \times$ TBE buffer for $1 \mathrm{~h}$, stained with ethidium bromide and visualize under ultraviolet light.

\section{Data analysis}

For each marker, allele number $(\mathrm{Na})$, allele frequency, observed heterozygosity $\left(H_{O}\right)$, expected heterozygosity $\left(H_{E}\right)$, Nei's unbiased genetic distance and genetic similarity between populations were calculated using POPGENE 


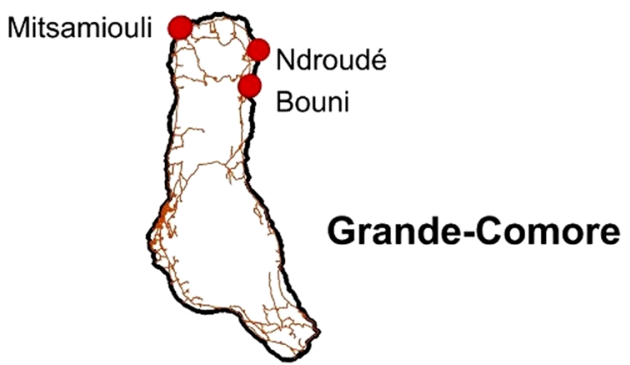

Moheli

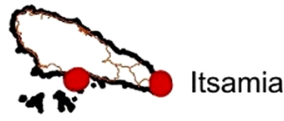

Nioumachoua

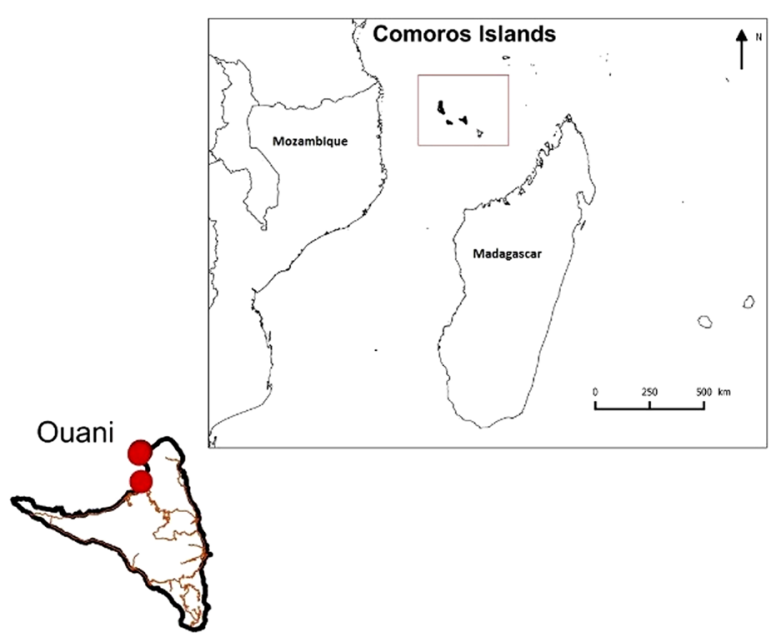

Anjouan
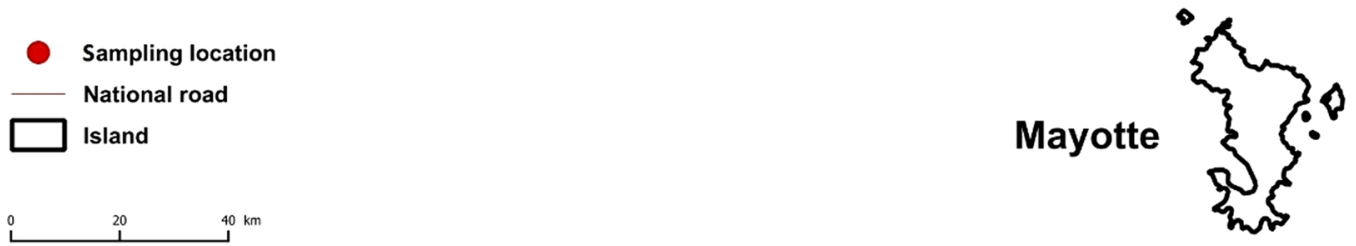

Fig. 1 Map showing the sampling collections of T. maxima in Comoros islands

Table 1 Sample details of T. maxima. For each sampling location, geographical coordinates, number (n) of individuals, shell length $(L)$ and collection time are shown

\begin{tabular}{|c|c|c|c|c|}
\hline Sample locality (abbreviation used) & Geographical coordinates & $\mathbf{n}$ & $\mathrm{L}(\mathrm{cm})$ & Collection time \\
\hline Grande-Comore (Gc) & From $11^{\circ} 23^{\prime} \mathrm{S}$ and $43^{\circ} 17^{\prime} \mathrm{E}$ to $11^{\circ} 29^{\prime} \mathrm{S}$ and $43^{\circ} 24^{\prime} \mathrm{E}$ & 24 & $16.85 \pm 4.34$ & June 2015 \\
\hline Moheli (Mo) & From $12^{\circ} 22^{\prime} \mathrm{S}$ and $43^{\circ} 44^{\prime} \mathrm{E}$ to $12^{\circ} 22^{\prime} \mathrm{S}$ and $43^{\circ} 52^{\prime} \mathrm{E}$ & 20 & $17.08 \pm 3.68$ & June 2015 \\
\hline Anjouan (An) & $12^{\circ} 05^{\prime} \mathrm{S}$ and $44^{\circ} 25^{\prime} \mathrm{E}$ & 28 & $18.80 \pm 5.50$ & June 2015 \\
\hline
\end{tabular}

1.32 (Yeh et al. 1999). Allele richness $\left(A_{R}\right)$ was carried out using FSTAT 2.9.3 (Goudet 2001). Hardy-Weinberg equilibrium (HWE) and linkage disequilibrium were conducted using or GENEPOP 4.2 program (Rousset 2008). Sequential Bonferroni correction was conducted to adjust the significant level (Holm 1979; Rice 1989). The presence of null allele was detected using MICORCHECKER 2.2.3 (Van Oosterhout et al. 2004). F-statistics $\left(F_{I S}, F_{S T}\right.$ and $\left.F_{I T}\right)$ and gene flow $(\mathrm{Nm})$ were calculated using GENETIX 4.05. Hierarchical Analysis of Molecular Variance (AMOVA) was conducted with ARLEQUIN 3.5 (Excoffier and Lischer 2010) to investigate regional population differentiation. Cluster analysis was performed to construct dendrogram using the unweighted pair group method average (UPGMA) by MEGA 6.06.

\section{Results}

Among 72 individuals, a total of 51 alleles were detected. The alleles number per locus ranged from 2 to 8 (mean $=5.6$ ). Overall, Mo specimens showed the highest $H_{O}$ and $H_{E}, 0.460$ and 0.715 , respectively. While Gc had the lowest value of $H_{O}$ and $H_{E}, 0.320$ and 0.695 , respectively (Table 4). Specimens from Mo revealed the highest mean value of Allelic richness $\left(A_{R}=5.262\right)$.

Significant deviations from HWE $(\mathrm{P}<0.05)$ were detected in 21 cases of the 27 locus-population combination after Sequential Bonferroni correction (Table 2). Null alleles decreased the number of significant deviations from HWE from 21 to 12 locus-population. Linkage disequilibrium was significant in only 4 out of 36 pairwise comparisons at the $\mathrm{P}<0.05$ level (Tm23637 vs 
Table 2 Respective sequences of nine microsatellite loci of T. maxima developed by Grulois et al. (2014) using in our study

\begin{tabular}{|c|c|c|}
\hline Locus & Primer sequence $5^{\prime}-3^{\prime}$ & Size \\
\hline Tm06526 & $\begin{array}{l}\text { F:TCCCATTGAAAAGTCTACGCAC } \\
\text { R: GCTGCAGAAATTTGTTCGACATC }\end{array}$ & 263-295 \\
\hline $\operatorname{Tm} 11666$ & $\begin{array}{l}\text { F: ATCGCACTTCCGCTTTGATG } \\
\text { R: ATTTATCGTGAACCCTATATCGC }\end{array}$ & $217-253$ \\
\hline $\operatorname{Tm} 14538$ & $\begin{array}{l}\text { F: AGCCTAGAGAGAAATACAGAAAGG } \\
\text { R: GTCTCACCGAACTAGATCCCC }\end{array}$ & $88-120$ \\
\hline $\operatorname{Tm} 20025$ & $\begin{array}{l}\text { F: GCGCGAGAAATCTAAGGCAC } \\
\text { R: ACATCTGTAGAAAGTCTTGTTATCATC }\end{array}$ & $240-282$ \\
\hline $\operatorname{Tm} 23637$ & $\begin{array}{l}\text { F: GTCCTTGGGCAGGAGATTTTG } \\
\text { R: ACTCTGAGGGTGTTGATTGAC }\end{array}$ & $199-243$ \\
\hline $\operatorname{Tm} 23670$ & $\begin{array}{l}\text { F: GGTCGGTAGAGAAGGTGTCC } \\
\text { R: CCGCCTTCAAATCCATCCAC }\end{array}$ & $143-217$ \\
\hline $\operatorname{Tm} 24162$ & $\begin{array}{l}\text { F:TGGACAGATTCAGTGTCGGC } \\
\text { R: GACCGGTTTGAATGGAGCTG }\end{array}$ & $193-260$ \\
\hline $\operatorname{Tm} 24224$ & $\begin{array}{l}\text { F: TGTATGCCGTCCACAAAAGC } \\
\text { R:TTCGAAGAAAGTCCACACCG }\end{array}$ & $258-292$ \\
\hline $\operatorname{Tm} 25349$ & $\begin{array}{l}\text { F: TCCGTTTCCTATTGATGTTGTCC } \\
\text { R: CATCTCTGGCGGCAGTTTG }\end{array}$ & $105-133$ \\
\hline
\end{tabular}

Tm23670; Tm20025 vs Tm25349; Tm23637 vs Tm25349 and Tm24224 vs Tm25349), indicating virtually no linkage among loci.

F-statistics over all loci among all populations fixed the average values for $F_{I S}, F_{S T}$ and $F_{I T}$ at $0.460,0.090$ and 0.510 , respectively. Pairwise comparison revealed that $F_{S T}=0.090\left(0.05<F_{S T}<0.15\right)$ showed a moderate genetic differentiation among the three populations (Wright 1978) with significant level at $\mathrm{P}<0.05$ value. AMOVA analysis revealed that $48.9 \%$ of the genetic variation originated within individuals whereas among the populations, the variation showed only $8.9 \%$ (Table 3 ). The number of migrants per generation $(\mathrm{Nm})$ placed the mean value at 5.50 .

The distance matrix showed that populations from Gc and Mo had the smallest genetic distance (0.120) and the highest genetic similarity $(0.885)$ values, whereas Gc and An populations indicated the highest genetic distance $(0.480)$ and the smallest genetic similarity (0.620) (Table 6). Furthermore, the unweighted pair group method average dendrogram revealed that $\mathrm{Gc}$ and Mo populations clustered together and An population formed one group.

\section{Discussion}

\section{Genetic diversity and deviation from HWE}

Previous studies have indicated a high level of genetic diversity on T. maxima in Indo-Pacific Ocean (Ayala et al. 1973; Campbell et al. 1975; Nuryanto and Kochzius
Table 3 Pairwise $\boldsymbol{F}_{\text {st }}$ values (below diagonal) and number of migrants per generation (above diagonal) among three populations of T. maxima

\begin{tabular}{lllr}
\hline & Gc & An & Mo \\
\hline Gc & & 1.80 & 12.40 \\
An & $0.120^{*}$ & & 2.35 \\
Mo & $0.020^{*}$ & $0.095^{*}$ & \\
\hline
\end{tabular}

* Significant at $\mathrm{P}<0.05$

2009) and other species on Tridacnidae family (Kochzius and Nuryanto 2008; DeBoer and Barber 2010; Hui et al. 2011). This present study shows a high level of genetic diversity for the small giant clams $\left(H_{E}=0.699-0.714\right)$ within populations. Grulois et al. (2014) made the first attempt to investigate the genetic diversity of $T$. maxima using microsatellite markers, and observed a high value of expected heterozygosity $\left(H_{E}=0.591-0.935\right)$ in New Caledonia. Comparing these two populations of T. maxima, one from Comoros islands in West Indian Ocean showed lower genetic diversity than the population from New Caledonia in Pacific Ocean. Vicariance process due to Pleistocene sea level fluctuation might be the main factor to affect the genetic diversity among populations of indo-Pacific Ocean (Williams and Benzie 1998; Carpenter et al. 2011). Oceanographic conditions and limited larval dispersal distance could be also an important factors to explain the genetic variability of populations (Froukh and Kochzius 2007).

The phenomenon of heterozygote deficits relative to HWE in microsatellite survey is most common in marine bivalves (Lemer et al. 2011). Significant deviations have been reported in T. maxima populations (Grulois et al. 2014), also in others species of Tridacnidae family (DeBoer and Barber 2010; Hui et al. 2011; Tiavouane et al. 2014). In our study, six of the nine loci were deviated from HWE, and heterozygote deficiency was recorded for almost all loci and in all populations. Therefore, our data (positive $F_{I S}$ values in Table 4) suggested that inbreeding might occur. Additionally, deficits of heterozygotes in HWE tests could be caused by the presence of null alleles. Among the nine loci used in this present study, four including Tm11666, Tm23637, $\operatorname{Tm} 23670$ and $\operatorname{Tm} 24162$ showed a presence of null alleles by Micro-checker analysis. Null alleles are frequently detected in many studies of marine bivalves assessed by microsatellite analysis (Gruenthal and Burton 2008) and are randomly laid to different nucleotides in primers, which are unlikely to be eliminated from all individuals (Hedgecock et al. 2004). In addition, populations of Pacific oysters (Crassostrea gigas) showed heterozygote deficiencies due to null alleles at microsatellites loci 
Table 4 Allele number $\left(N_{A}\right)$, observed heterozygoty $\left(H_{O}\right)$, expected heterozygoty $\left(H_{E}\right)$, allelic richness $\left(A_{R}\right)$, population inbreeding coefficient $\left(F_{I S}\right)$ and Hardy-Weinberg equilibrium (HWE)

\begin{tabular}{|c|c|c|c|c|c|c|c|c|c|c|}
\hline \multirow[t]{3}{*}{ Site (code) } & \multicolumn{9}{|c|}{ GeneBank accession/locus } & \multirow[t]{3}{*}{ Mean } \\
\hline & KM267264 & KM267265 & KM267266 & KM267268 & KM267269 & KM267270 & KM267271 & KM267272 & KM267273 & \\
\hline & Tm06526 & $\operatorname{Tm} 11666$ & $\operatorname{Tm} 14538$ & $\operatorname{Tm} 20025$ & $\operatorname{Tm} 23637$ & $\operatorname{Tm} 23670$ & $\operatorname{Tm} 24162$ & $\operatorname{Tm} 24224$ & $\operatorname{Tm} 25349$ & \\
\hline \multicolumn{11}{|c|}{ Grande Comore (Gc) } \\
\hline$N_{A}$ & 6 & 6 & 5 & 5 & 5 & 4 & 5 & 5 & 2 & 4.777 \\
\hline$H_{O}$ & 0.444 & 0.350 & 0.500 & 0.761 & 0.090 & 0.318 & 0.368 & 0.050 & 0.000 & 0.320 \\
\hline$H_{E}$ & 0.836 & 0.792 & 0.794 & 0.794 & 0.778 & 0.760 & 0.763 & 0.783 & 0.102 & 0.695 \\
\hline$A_{R}$ & 5.997 & 5.692 & 4.998 & 4.998 & 4.904 & 4.000 & 4.992 & 4.942 & 1.960 & 4.720 \\
\hline$F_{15}$ & 0.568 & 0.555 & 0.580 & 0.628 & 0.510 & 0.552 & 0.560 & 0.502 & 0.549 & 0.555 \\
\hline HWE (P value) & 0.000 & 0.007 & 0.008 & 0.525 & 0.000 & 0.000 & 0.000 & 0.000 & 0.0280 & - \\
\hline \multicolumn{11}{|l|}{ Anjouan (An) } \\
\hline$N_{A}$ & 5 & 6 & 8 & 4 & 6 & 4 & 5 & 4 & 3 & 5 \\
\hline$H_{O}$ & 0.708 & 0.480 & 0.478 & 0.777 & 0.153 & 0.407 & 0.440 & 0.000 & 0.000 & 0.382 \\
\hline$H_{E}$ & 0.778 & 0.766 & 0.848 & 0.754 & 0.725 & 0.748 & 0.721 & 0.728 & 0.222 & 0.699 \\
\hline$A_{R}$ & 4.953 & 5.444 & 7.419 & 4.000 & 5.228 & 4.000 & 4.883 & 3.998 & 2.824 & 4.750 \\
\hline$F_{15}$ & 0.509 & 0.468 & 0.460 & 0.525 & 0.414 & 0.459 & 0.465 & 0.385 & 0.438 & 0.460 \\
\hline HWE (Pvalue) & 0.143 & 0.000 & 0.002 & 0.692 & 0.000 & 0.000 & 0.019 & 0.000 & 0.000 & - \\
\hline \multicolumn{11}{|l|}{ Moheli (Mo) } \\
\hline$N_{A}$ & 5 & 7 & 7 & 5 & 7 & 4 & 5 & 5 & 3 & 5.333 \\
\hline$H_{O}$ & 0.800 & 0.250 & 0.588 & 0.833 & 0.611 & 0.470 & 0.466 & 0.117 & 0.000 & 0.460 \\
\hline$H_{E}$ & 0.802 & 0.681 & 0.714 & 0.804 & 0.850 & 0.768 & 0.726 & 0.736 & 0.349 & 0.715 \\
\hline$A_{R}$ & 5.000 & 6.810 & 6.850 & 5.000 & 6.833 & 4.000 & 5.000 & 4.872 & 3.000 & 5.262 \\
\hline$F_{15}$ & 0.415 & 0.331 & 0.387 & 0.420 & 0.376 & 0.360 & 0.364 & 0.302 & 0.327 & 0.365 \\
\hline HWE (Pvalue) & 0.4441 & 0.000 & 0.270 & 0.479 & 0.000 & 0.003 & 0.000 & 0.000 & 0.000 & - \\
\hline
\end{tabular}

Value in italic indicates significant deviations from HWE $(P<0.05)$ after sequential Bonferroni corrections

(Hedgecock et al. 2004), which is similar with the results of T. maxima (Grulois et al. 2014). Therefore, it seems likely that null alleles may be the major cause of heterozygotes deficiencies.

\section{Genetic differentiation among populations}

$F_{S T}, N m$ and genetic distance are commonly used to measure the genetic differentiation. Indeed, our data showed that genetic differentiation was moderate among all populations from global pairwise $F_{S T}$ value. AMOVA also indicated that most variation is attributed to genetic difference within individuals (48.9\%), while variation among populations is low, accounting for only $8.9 \%$ of the total variations (Table 5). Hence, it is indicating the presence of genetic heterogeneity among these three populations. Therefore, the assumption of panmixia was rejected among all populations. In addition, our data have revealed an average gene flow value (5.51) greater than 1, confirming genetic drift is not the factor to explain the genetic exchanges between these populations (Slatkin 1985). Therefore, due to the sedentary of $T$. maxima such as others marine bivalves, larval dispersal can be the main factor influencing gene flow and population differentiation. Although it was demonstrated that $T$. maxima have pelagic larvae dispersal about 9 days (Lucas 1988) to travel long distance about $500 \mathrm{~km}$, which means

Table 5 AMOVA analysis for three populations of T. maxima

\begin{tabular}{lccc}
\hline Source of variation & d.f. & Sum of squares & Variance components \\
\hline Among populations & 2 & 34.151 & 0.315 \\
Among individuals within populations & 67 & 278.063 & 1.491 \\
Within individuals & 70 & 107.000 & 1.727 \\
Total & 139 & 419.214 & 3.534
\end{tabular}

* Significant at $\mathrm{P}<0.05$ 
Table 6 Nei's unbiased genetic similarity (above diagonal) and genetic distance (below diagonal)

\begin{tabular}{llll}
\hline & Gc & An & Mo \\
\hline Gc & & 0.620 & 0.885 \\
An & 0.480 & & 0.690 \\
Mo & 0.120 & 0.350 & \\
\hline
\end{tabular}

that population differentiation should become detectable among the three islands (approximately $80 \mathrm{~km}$ between them). However, gene flow along the dispersal route between Gc and An islands is lower than that between Gc and Mo islands, and also Mo and An islands (Table 4). It indicates limited larval dispersal and geographic barriers like marine currents restricted gene exchanges among these islands. Additionally, the topology of the UPGMA tree (Fig. 2) and the genetic distance (Table 6) also suggested that gene flow between Gc and An populations was limited and barriers to genetic exchanges might exist among these two populations. Moreover, another possible reason to explain the high gene flow and the clustering between the populations of Gc and Mo could be caused by the angling boats traffic massive moving between the two lands, suggesting the high larval dispersal.

\section{Implication for conservation}

Tridacnid species are listed in Appendix II of CITES and are classified as vulnerable on the IUCN Red List of Threatened Species due to their extreme exploitation for the food and marine ornamental trade. According to the CITES data, international trade of Giant clams noncaptive bred increased from about 40,000 to 100,000 individuals between 1993 and 2001 (Wabnitz et al. 2003). In Comoros islands, despite the existence of the legislations for marine resources, T. maxima were especially exploited for food and their big shells were used for different purposes such as ornamental objects. Furthermore, over-exploitation, pollution, reef degradation by trampling or destructive fishing practices, and coral bleaching event due to rising sea temperature by El-nino event in 1997/1998 are likely to lead negative effects (ASCLME 2012). Therefore, one protected area (Moheli Marine Park) covering a total area of $403.6 \mathrm{~km}^{2}$ was

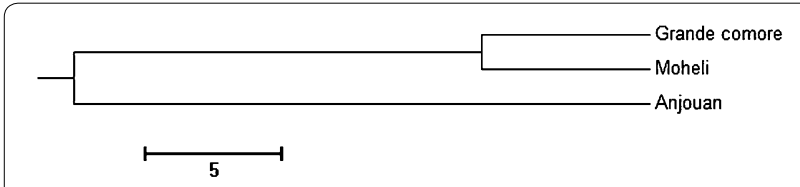

Fig. 2 Unweighted pair group method average dendrogram (UPGMA) based on Nei's Genetic distance among population created in Comoros to ensure the sustainable use of living marine resources (Beudard 2003).

In our study, the genetic diversity in the three islands showed that population from Mo $\left(H_{E}=0.714 ; A_{R}=5.26\right)$ is higher than $\mathrm{Gc}$ and $\mathrm{An}\left(H_{E}=0.694 ; A_{R}=4.720\right.$, $\left.H_{E}=0.699 ; A_{R}=4.75\right)$, respectively. The protection of the area could be the major factor to explain high genetic diversity in Mo population. As there is a Marine national park in Moheli (Beudard 2003), species in the island benefit from its protection. Compared to the others islands where there are not restricted of any specific protection, Moheli is genetically more diverse, which can play an important role for allele distribution in the others islands. Therefore, Moheli Marine Park is most probably insufficient for the protection of T. maxima. While they have a larval dispersal time about 9 days, specimens of T. maxima are able to travel a distance about $500 \mathrm{~km}$. Even though the populations between Gc and An showed low larval dispersal, it is possible to detect a connectivity for populations among the three islands from Comoros because of their small scale area. Therefore, further studies based on oceanographic barriers and ecological barriers in addition to genetic data are more important to understand the marine organism movements and connectivity between the islands. The genetic diversity and population differentiation of T. maxima can offer useful information to establish an effective plan for conservation management.

\section{Authors' contributions}

NAM carried out the experimental work, data analysis and interpretation of all genetic data, and drafted the manuscript. QY and LP assisted the experimental work and data analysis. MIC collected the samples of T. maxima. SW, XH and $Z B$ have reviewed and have involved in drafting the manuscript. All authors read and approved the final manuscript.

\section{Author details}

${ }^{1}$ Key Laboratory of Marine Genetics and Breeding, College of Marine Life Sciences, Ocean University of China, Qingdao 266003, China. ${ }^{2}$ Faculty of Sciences and Technology, University of Comoros, BP 2585, Moroni Corniche, Comoros.

\section{Acknowledgements}

We gratefully thank the Ministry of Environment of Comoros and the Faculty of Sciences and Technology, University of Comoros especially the LBEPA (Laboratoire de Biologie, Ecologie et Physiologie Animales) who provided the CITES export permit (No. 003/KM/15/DNEF) for expedition of T. maxima. Thanks to the staff of Marine Park of Moheli and fishermen of different islands for their help to obtain the samples. We would also to thank Athoumani

Artadji for help to draw the map and the anonymous reviewers for their valuable comments and corrections. This work was supported by the Earmarked Fund for Modern Agro-Industry Technology Research System (CARS-48), Seed Improvement Project of Shandong Province and the National Infrastructure of Fishery Germplasm Resources.

\section{Competing interests \\ The authors declare that they have no competing interests.}

\section{Ethics, consent and permissions}

All the procedures involved in handling and treatment of small giant clams during this study were approved by the Ocean University of China Institutional Animal Care and Use Committee (OUC-IACUC) prior to the initiation of the study. 
Received: 25 May 2016 Accepted: 11 October 2016

Published online: 22 October 2016

\section{References}

ASCLME (2012) National Marine Ecosystem Diagnostic Analysis. Comoros. Contribution to the Agulhas and Somali Current Large Marine Ecosystems Project (supported by UNDP with GEF grant financing)

Ayala FJ, Hedgecock D, Zumwalt GS, Valentine JW (1973) Genetic variation in Tridacna maxima, an ecological analog of some unsuccessful evolutionary lineages. Evolution 27(2):177-191

Benzie J, Williams S (1992a) No genetic differentiation of giant clam (Tridacna gigas) populations in the Great Barrier Reef, Australia. Mar Biol 113:373-377

Benzie JA, Williams ST (1992b) Genetic structure of giant clam (Tridacna maxima) populations from reefs in the Western Coral Sea. Coral Reefs 11:135-141

Beudard F (2003) Contribution à l'étude des herbiers à phanérogames marines du Parc Marin de Mohéli (Archipel des Comores). Université de La Réunion, Maitrise

bin Othman AS, Goh GH, Todd PA (2010) The distribution and status of giant clams (family Tridacnidae) — a short review. Raffles Bull Zool 58:103-111

Campbell C, Valentine J, Ayala F (1975) High genetic variability in a population of Tridacna maxima from the Great Barrier Reef. Mar Biol 33:341-345

Carpenter KE et al (2011) Comparative phylogeography of the coral triangle and implications for marine management. J Mar Biol 2011:1-14. doi:10.1155/2011/396982

DeBoer TS, Barber PH (2010) Isolation and characterization of 9 polymorphic microsatellite markers for the endangered boring giant clam (Tridacna crocea) and cross-priming testing in three other Tridacnid species. Conserv Genet Resour 2:353-356. doi:10.1007/s12686-010-9249-7

Deuss M, Richard G, Verneau N (2013) Mollusques de Mayotte. Naturalistes de Mayotte, Mamoudzou (Mayotte)

Excoffier L, Lischer HE (2010) Arlequin suite ver 3.5: a new series of programs to perform population genetics analyses under Linux and Windows. Mol Ecol Resour 10:564-567

Froukh T, Kochzius M (2007) Genetic population structure of the endemic fourline wrasse (Larabicus quadrilineatus) suggests limited larval dispersal distances in the Red Sea. Mol Ecol 16:1359-1367. doi:10.1111/j.1365-294X.2007.03236.x

Goudet (2001) FASAT, a program to estimate and test gene diversities and fixation indices (version 2.9.3). Department of Ecology and Evolution, University of Lausanne, Switzerland. http://www2.unil.ch/popgen/softwares. Accessed 24 Dec 2015

Gruenthal KM, Burton RS (2008) Genetic structure of natural populations of the California black abalone (Haliotis cracherodii Leach, 1814), a candidate for endangered species status. J Exp Mar Biol Ecol 355:47-58. doi:10.1016/j. jembe.2007.11.013

Grulois D, Tiavouane J, Dumas PP, Fauvelot C (2014) Isolation and characterization of fifteen microsatellite loci for the giant clam Tridacna maxima. Conserv Genet Resour 7:73-75. doi:10.1007/s12686-014-0290-9

Hart AM, Bell JD, Foyle TP (1998) Growth and survival of the giant clams, Tridacna derasa, T. maxima and T. crocea, at village farms in the Solomon Islands. Aquaculture 165:203-220

Hedgecock D, Li G, Hubert S, Bucklin K, Ribes V (2004) Widespread null alleles and poor cross-species amplification of microsatellite DNA loci cloned from the Pacific oyster, Crassostrea gigas. J Shellfish Res 23:379-386

Holm S (1979) A simple sequentially rejective multiple test procedure. Scand J Stat 6(2):65-70

Hui M, Kochzius M, Leese F (2011) Isolation and characterisation of nine microsatellite markers in the boring giant clam (Tridacna crocea) and crossamplification in five other tridacnid species. Mar Biodivers 42:285-287. doi:10.1007/s12526-011-0101-4
Jameson SC (1976) Early life history of the giant clams Tridacna crocea Lamarck, Tridacna maxima (Röding), and Hippopus hippopus (Linnaeus). Pac Sci 30:219-233

Kochzius M, Nuryanto A (2008) Strong genetic population structure in the boring giant clam, Tridacna crocea, across the Indo-Malay Archipelago: implications related to evolutionary processes and connectivity. Mol Ecol 17:3775-3787. doi:10.1111/j.1365-294X.2008.03803.x

Laurent V, Planes S, Salvat B (2002) High variability of genetic pattern in giant clam (Tridacna maxima) populations within French Polynesia. Biol J Linn Soc 77:221-231

Lemer S, Rochel E, Planes S (2011) Correction method for null alleles in species with variable microsatellite flanking regions, a case study of the black-lipped pearl oyster Pinctada margaritifera. J Hered 102:243-246. doi:10.1093/jhered/esq123

Lucas J (1988) Giant clams: description, distribution and life history. Giant clams in Asia and the Pacific ACIAR Monograph No. 9, pp 21-33

Lucas JS (1994) The biology, exploitation, and mariculture of giant clams (Tridacnidae). Rev Fish Sci 2:181-223

Nuryanto A, Kochzius M (2009) Highly restricted gene flow and deep evolutionary lineages in the giant clam Tridacna maxima. Coral Reefs 28:607-619. doi:10.1007/s00338-009-0483-y

Rice WR (1989) Analyzing tables of statistical tests. Evolution 43:223-225

Rousset F (2008) GENEPOP'007: a complete re-implementation of the genepop software for Windows and Linux. Mol Ecol Resour 8:103-106

Schneider JA, Foighil DÓ (1999) Phylogeny of giant clams (Cardiidae: Tridacninae) based on partial mitochondrial 16S rDNA gene sequences. Mol Phylogenet Evol 13:59-66

Slatkin M (1985) Gene flow in natural populations. Annu Rev Ecol Syst 16:393-430

Smith SD (2011) Growth and population dynamics of the giant clam Tridacna maxima (Röding) at its southern limit of distribution in coastal, subtropical eastern Australia. Molluscan Res 31:37

Soo P, Todd PA (2014) The behaviour of giant clams (Bivalvia: Cardiidae: Tridacninae). Mar Biol 161:2699-2717. doi:10.1007/s00227-014-2545-0

Su Y, Hung J, Kubo H, Liu L (2014) Tridacna noae (Röding, 1798)-a valid giant clam species separated from T. maxima (Röding, 1798) by morphological and genetic data. Raffles Bull Zool 62:124-135

Tiavouane J, Jacob T, Dumas PP, Fauvelot C (2014) Isolation and characterization of fifteen microsatellite loci for the giant clam Hippopus hippopus (family Tridacnidae). Conserv Genet Resour 6:735-737. doi:10.1007/ s12686-014-0203-y

Toonen RJ, Nakayama T, Ogawa T, Rossiter A, Delbeek JC (2011) Growth of cultured giant clams (Tridacna spp.) in low pH, high-nutrient seawater: species-specific effects of substrate and supplemental feeding under acidification. J Mar Biol Assoc UK 92:731-740. doi:10.1017/ s0025315411000762

Van Oosterhout C, Hutchinson WF, Wills DP, Shipley P (2004) MICRO-CHECKER: software for identifying and correcting genotyping errors in microsatellite data. Mol Ecol Notes 4:535-538

Wabnitz C, Taylor M, Green E, Razak T (2003) The global trade in marine ornamental species. UNEP World Conservation Monitoring Centre, Cambridge

Williams S, Benzie J (1998) Evidence of a biogeographic break between populations of a high dispersal starfish: congruent regions within the Indo-West Pacific defined by color morphs, mtDNA, and allozyme data. Evolution 52:87-99

Wright S (1978) Evolution and genetics of populations. Variability within and among natural populations, vol 4. University of Chicago Press, Chicago

Yeh F, Yang R, Boyle T (1999) POPGENE Version 132, Microsoft window base software for population genetic analysis, a quick user's guide, vol 17. University of Alberta, Center for International Forestry Research, Alberta

Zhan A et al (2009) Fine-scale population genetic structure of Zhikong scallop (Chlamys farreri): do local marine currents drive geographical differentiation? Mar Biotechnol 11:223-235 